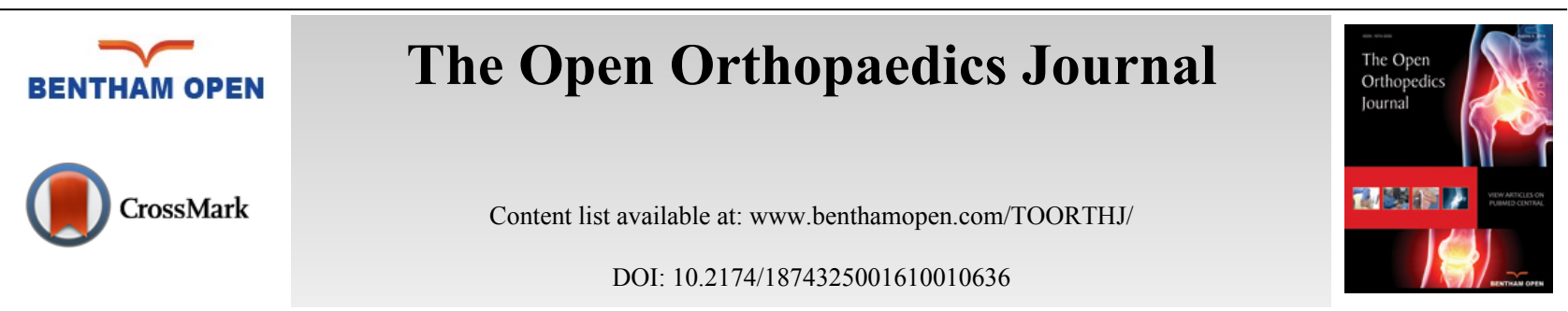

REVIEW ARTICLE

\title{
Biofilm and the Role of Antibiotics in the Treatment of Periprosthetic Hip and Knee Joint Infections
}

\author{
Yusuf H. Mirza ${ }^{1, *}$, Rosamond Tansey ${ }^{1}$, Mohamed Sukeik², Mohammed Shaath ${ }^{3}$ and Fares Sami \\ Haddad $^{1}$ \\ ${ }^{I}$ Department of Trauma and Orthopaedics, University College London Hospital, 235 Euston Road, NW1 2BU, London, \\ United Kingdom \\ ${ }^{2}$ Department of Trauma and Orthopaedics, Royal London Hospital, Whitechapel, London, E1 1BB, United Kingdom \\ ${ }^{3}$ Department of Trauma and Orthopaedics, North Manchester General Hospital, Delaunay's Road, Crumpsall, M8 \\ $5 R B$, United Kingdom
}

Received: March 12, 2016

Revised: June 17, 2016

Accepted: July 15, 2016

\begin{abstract}
An increasing demand for lower limb arthroplasty will lead to a proportionate increase in the need for revision surgery. A notable proportion of revision surgery is secondary to periprosthetic joint infections (PJI). Diagnosing and eradicating PJI can form a very difficult challenge. An important cause of PJI is the formation of a bacterial biofilm on the implant surface. Our review article seeks to describe biofilms; their definitions and formation, common causative bacteria, prophylactic and therapeutic antibiotic therapy.
\end{abstract}

Keywords: Antibiotics, Biofilm, Periprosthetic joint infection, Total hip arthroplasty, Total knee arthroplasty.

\section{INTRODUCTION}

With an increasingly ageing population and rising levels of obesity, an increase in the number of lower limb primary and revision arthroplasties can be anticipated [1]. Prosthetic Joint Infection (PJI) is a common indication for hip and knee revision surgery, constituting $15 \%$ of all revision hip and $25 \%$ of all revision knee procedures [2]. PJIs are distressing to the patient, who may undergo multiple surgeries with prolonged hospital stay and suffer the side effects of long term antibiotic treatment. Furthermore, patients report a poorer quality of life and levels of function in comparison to those who undergo uncomplicated primary procedures [3]. PJI management has significant financial implications with an estimated cost of $€ 32,000$ per patient for revision surgery; approximately 3.6 times greater than that of the primary surgery [4]. PJIs are therefore greatly feared amongst patients and the operating surgeons.

In Sir John Charnley's era, an incidence of $9.5 \%$ of PJI was observed in the United Kingdom (UK). This has now decreased to $2 \%$ in primary total knee arthroplasty (TKA) and $0.45-0.57 \%$ in primary total hip arthroplasty (THA) [5]. The incidence of PJI after revision arthroplasty is far higher [6]. Risk factors for PJI can be classified as patient or surgery related. Poultsides et al. [7] reported that independent risk factors for surgical site infection (SSI) related to the patient included male sex, ethnicity, age $<44$, liver disease, excess alcohol intake, coagulopathy, chronic lung disease and complicated diabetes. From a surgical viewpoint, a careful analysis of perioperative methods led to the implementation of various measures to improve infection control. This included the introduction of laminar air flow and prophylactic antibiotics, minimizing the number of staff present intraoperatively and limiting unnecessary entry and exit into the operating room and improving surgical times $[8,9]$.

\footnotetext{
* Address correspondence to this author at the Department of Trauma and Orthopaedics, University College Hospital London, 235 Euston Road, NW1 2BU, London, United Kingdom; Tel: 0044 (0) 7530271137; E-mail: mirzyusuf@gmail.com
} 
PJI management is challenging for a number of reasons. Until recently, there has been no consensus as to what constituted a PJI and this in turn hindered correct diagnosis and further treatment. The confusion is further complicated by the fact that no single investigation accurately confirms a PJI. The recent Musculoskeletal Infection Society classification [9] has sought to rectify this. Surgical treatment is guided by confirmation of the causative organism and its characteristics which may not always be feasible. It is crucial to understand the patient's pre morbid function, prior medical history including any immunocompromised condition and expectations for further surgical treatment. PJI should be dealt with urgently as there is only a short period during which the biofilm, a product of the infecting bacteria may still be in a nascent form and thus easier to eradicate. Once established, the biofilm is difficult to eliminate and confers a number of advantages to the bacteria at the expense of the host.

The aim of this review is to discuss biofilms and their role in PJI including pathogenesis as well as the infecting bacteria and the role of prophylactic and therapeutic antibiotics.

\section{IMPLANTS AND THE BIOFILM}

The implantation of prostheses itself predisposes to infections and makes it more difficult to control already established infections. In Zimmerli's classic animal model experiment [10], a population of guinea pigs had subcutaneous, rigid and perforated polymethacralate and polytetrafluoroethylene tubes implanted. In those which had the tubes removed, no abscesses developed, whilst those in which the implants remained developed infection in $95 \%$ of the population. The same experiment also suggested a decreased ability for opsonization in the presence of the implant as well as decreased bactericidal properties of polymorphonuclear leukocytes (PMNLs). The avascular nature of the implant prevents the access of cells facilitating the immunological response to bacteria. Furthermore, the presence of the implant reduced the minimal dose of Staph Aureus required to form an abscess by 10,000 folds from $10^{6}$ to $10^{2}$. Surrounding the implant is an area described as the immuno-incompetent fibroinflammatory zone [11, 12]. Within this zone, any cellular immune responses initiated result in the formation of superoxide radicals and cytokine mediated activity causing damage to the surrounding tissues and bringing about implant loosening [12].

Biofilms play a crucial role in the pathogenesis of PJI and make its eradication difficult. They are described as a complex network of sessile bacteria organized in micro colonies, within a highly hydrated polymeric matrix [13]. The properties of sessile bacteria completely differ to that of planktonic bacteria, the free floating single celled organism. Susceptibility of the bacteria to antibiotics is reduced within the first 2 weeks of infection, owing to their sessile and slow growing nature. The bacteria receive nutritional support from the surrounding matrix which contains a glycocalyx of polysaccharides, protein and DNA. The high density of bacteria in a biofilm leads to the phenomenon of quorum sensing. Through this microorganisms can communicate with each other; regulating expression and production of virulence factors. This prevents biofilm eradication and potentially contributes to the destruction of surrounding tissues [14]. Antimicrobial agents as a result, become limited by their inability to penetrate the full thickness of the biofilm and diffuse adequately. Bacteria can be introduced intraoperatively, during implantation, or spread by hematogenous seeding. Gristina et al. [15] describes a "race for the surface" when both bacterial and host cells compete at the expense of one another in colonizing the implant surface. A biofilm is fully developed after four stages: adherence, accumulation, maturation and dispersal. The mechanism by which bacteria adhere to the implant is not completely understood. Bacteria contain adhesins, a cell surface component which facilitates adherence to the biomaterial. The specific group of adhesins involved in the facilitation of binding of the bacteria to the implant are called microbial surface component recognizing adhesive matrix molecules (MSCRAMMS). Each molecule is specific for different types of tissue and the adherence of the bacteria to the tissue [16]. The implant, becomes coated in serum proteins which include amongst others, fibronectin and collagen. The bacterial MSCRAMM recognizes the serum protein and binds to it accordingly. The most commonly examined MSCRAMM in Staphylococcus Epidermidis infections is a fibronectin binding protein called sDRG. The deletion of this protein prevents adherence of the bacteria in experiments performed both in vitro and vivo [17]. Two stages have been identified in bacterial adherence to an implant surface. The first which is reversible is known as the physico-chemical stage. Through this stage the bacteria is brought into contact with the implant surface via van der Waals forces, electrostatic attraction and gravitational forces. The second stage which is known as the molecular-cellular stage occurs when the bacteria attach irreversibly to the surface. These stages create a satisfactory environment for the production of biofilm. The subsequent deposition of the extracellular polysaccharide matrix provides nutrition to the bacteria whilst protecting them from the immunological response. The second stage varies according to the causative bacteria. For example, Staphylococcus Aureus binds to host proteins such as fibronectin, whereas Staphylococcus Epidermidis is more dependent on the type of prosthetic material [10, 14]. The most widely studied MSCRAMM with a critical role is polysaccharide intercellular adhesin (PIA). PIA is responsible 
for the pathogenesis of the extracellular matrix which prevents successful antimicrobial action and promotes bacteriumbacterium adhesion [16]. It also inhibits neutrophil dependent bactericides and plays an important role in the architecture of the mature biofilm [17]. The mechanism by which biofilms modulate the actions of the innate immune system cells remains unknown. Scherr et al. [18, 19] reported that examination of the transcriptome, revealed a down regulation of 550 staphylococcal genes within an hour, upon exposure to macrophages. Interestingly, there was no phagocytic activity of the macrophages at the time of down-regulation whereas after 24 hours when the macrophages had died, the suppression of transcriptional activity ceased. This finding suggests an attempt by biofilms to conceal themselves from the host immune response. Biofilm response to neutrophils differs markedly. There is no reduction in the transcriptome analysis upon exposure to neutrophils which tend to invade the biofilm in greater numbers and display signs of phagocytosis whilst remaining viable $[18,19]$. In spite of this, there is no reduction in bacterial burden observed in vitro or in vivo studies.

The actions of both neutrophils and macrophages broadly overlap. Macrophages portray phagocytic activity like neutrophils, yet in addition play an important role in adaptive immunity. They play a crucial role in cell signaling; alerting $\mathrm{T}$ cells to the presence of bacteria and propagating the adaptive immune response. It is not clear why the transcriptional action of Staphylococcus Aureus behaves differently with different phagocytic cell types, but it has been suggested that Staphylococcus Aureus can "hide" intracellularly in neutrophils.

As the biofilm increases in size, planktonic bacteria are released, subsequently forming secondary colonies [14].

\section{MICROBIOLOGY}

The most common organisms implicated in PJIs are Gram positives including Staphylococcus Aureus and coagulase negative Staphylococci (CNS) which cause 50-60\% of all infections and are well known to form biofilms [16, 20].

\section{Staphylococcus Aureus}

This is a commensal organism, found most commonly within the nares and the skin flora. It is more virulent than CNS, with the ability to synthesize toxins and virulence factors and causes a variety of infections including endocarditis, osteomyelitis and PJIs and toxic shock syndrome. An overall $30 \%$ of the population is colonized with either methicillin sensitive or methicillin resistant strains and this has been reported as an independent risk factor for development of SSIs [21, 22]. Staphylococcus Aureus carriage has been classified into 3 groups: intermittent carriers with changing strains (60\%), carriers of a single persistent strain (20\%) and non-carriers (20\%) [23]. An increase in Staphylococcus Aureus colonization is noted in insulin dependent diabetics, intravenous drug users and patients on dialysis. This is thought to be due to the regular skin punctures, which is further supported by the high colonization rates observed in otherwise medically well patients who administer allergy injections [21]. This high rate is also noted in patients with human immunodeficiency virus but the exact pathogenesis remains unknown [21].

\section{Methicillin Resistant Staphylococcus Aureus (MRSA)}

Originally reported in 1961 in the UK, MRSA was believed to be a nosocomial infection related to misuse of antibiotics which was confined to immunocompromised inpatients and patients with indwelling devices [24]. The methicillin resistant status of MRSA is conferred by the presence of a penicillin binding protein called PBP2A, coded for by the mecA gene on the staphylococcal chromosomal cassette [24]. This protein renders all beta lactam antibiotics inactive including flucloxacillin, co amoxiclav and piperacillin tazobactam. Other groups affected include cephalosporins (notably cefuroxime) and carbapenems (meropenem). More recently a community acquired strain of MRSA which is not related to hospital admissions, known as c-MRSA has been discovered. Analysis reveals a different genotype to hospital acquired MRSA. C-MRSA predominantly affects younger and healthier patients [25].

As with other staphylococci, both coagulase negative and positive, MRSA is a hardy organism; allowing it to survive outside of the human host. This stems from its ability to resist desiccation, changes in temperature, humidity and exposure to sunlight [26]. MRSA when mixed with dust for example is still viable up to a year after inoculation, allowing for an increased likelihood of the bacteria being transferred to a new host [26]. However, the main route of transmission for MRSA is by direct skin contact with colonized or infected patients, healthcare workers or by oro-nasal droplet spray. In an effort to prevent transmission, NICE has recommended frequent hand washing and emphasized this through several high profile awareness campaigns within the UK National Health Service [27]. With MRSA colonizing $5.3 \%$ of all patients admitted for elective orthopaedic surgery, efforts to address its transmission have also involved prophylaxis. Since April 2009, the Department of Health in the UK has screened all elective surgical admissions 
attending general practitioners surgery and pre-operative assessment clinics for MRSA taking swabs from the nares, throat, groin and axilla. MRSA positive patients are treated with topical mupirocin $2 \%$, administered nasally for five days and daily baths with $4 \%$ chlorhexidine. A $0.2 \%$ chlorhexidine mouth wash is also prescribed if the pharyngeal swab grows MRSA.

Murphy et al. [28] evaluated the relationship between MRSA colonization, after successful eradication, and subsequent SSI in patients admitted for elective lower limb arthroplasty. The study demonstrated that the overall rate of MRSA SSIs, in those with negative MRSA screens on admission, was $1.1 \%$ in THA and $0.4 \%$ in TKA. It was suggested that those with a positive MRSA screen have a significant risk of subsequent SSI, with MRSA being the most likely causative organism. The study raises important questions regarding antibiotic prophylaxis in those with a positive screen for MRSA. Given that implant surgery is high risk, conventional antibiotic regimens cannot be used and hence Murphy et al. altered their practice, adding teicoplanin to the usual cefuroxime regimen [28].

\section{Staphylococcus Epidermidis}

Staphylococcus Epidermidis is a coagulase negative bacterium known for its ability to mediate infection on indwelling devices. It is an opportunistic organism, previously thought to be harmless, and frequently found as a commensal on the skin and mucous membranes.

Its presence is suspected to prevent the attachment of more virulent organisms such as Staphylococcus Aureus. It is well known for its ability to form a biofilm. However, the exact pathogenesis is unknown but the most plausible hypothesis is that it has developed mechanisms to nullify the innate host response.

Other common pathogens include Streptococcus and Gram Negative Bacilli (GNB). Peel et al. [29] reported that GNB and enterococcal species are more likely to occur in polymicrobial PJIs. Biofilms are most commonly formed by staphylococci and streptococci, but the ability to form them has also been observed with Pseudomonas Aeruginosa, a bacterium colonizing most cystic fibrosis patients.

\section{ANTIBIOTIC THERAPY}

\section{Prophylaxis}

Prophylactic antibiotics are defined as those given before, during or after surgery to prevent infection. Current UK practice suggests that prophylactic antimicrobial agents should cover expected pathogens, take into account local resistance patterns and have a narrow spectrum whilst considering cost [30].

Historically prophylactic antibiotics have erroneously been suggested to cause a two fold increase in infective complications and thus were not initially used. However this was based on flawed research which was later discredited with Fogelberg et al. [31] demonstrating a fourfold reduction of infections in patients given perioperative penicillin, compared to a control group receiving no antibiotics. Meehan et al. [32] investigated the optimal time for prophylactic antibiotic administration in an animal model and reported that bactericidal action was most favorable when antibiotics were present within tissues prior to surgery.

Current guidance obtained from consensus between the Centre for Disease Control (CDC) and the American Association of Orthopaedic Surgeons (AAOS) recommends administration of prophylactic antibiotics an hour prior to incision and continuing antibiotics for 24 hours postoperatively [33]. Cephalosporins including cefuroxime and cefazolin are the most commonly prescribed prophylactic antibiotics as per AAOS recommendation due to broad spectrum coverage against penicillinase producing methicillin susceptible Gram positive staphylococci and streptococci. Alternatives for allergic patients include clindamycin and vancomycin [34]. Cefazolin, a first generation cephalosporin, also covers some Gram negatives such as Proteus mirabilis, Escherichia Coli and Klebsiella whereas cefuroxime, a second generation cephalosporin also covers Haemophilus influenzae, Enterobacter and Neisseriae. There are numerous benefits to using cephalosporins as they cover most organisms encountered in orthopaedic surgery. Furthermore, they have a proven evidence base, good safety profile and are inexpensive. The UK has recently however seen a trend away from using cephalosporins [35]. In 2011, Aujla et al. sent a questionnaire to 195 acute care trusts in the UK enquiring about antibiotic prophylaxis in elective and trauma patients and reasons if new regimes were adopted [35]. The most popular regimes used were cefuroxime alone, flucloxacillin and gentamicin, and co-amoxiclav. The reasons for adopting new regimes included the fear of Clostridium difficile infection secondary to cephalosporin use, the desire to reduce dependence on cephalosporins and local microbiology advice. Interestingly, Jenkins et al. [36] 
reported only 1.7 episodes of Clostridium Difficile infection in 1000 cases of primary elective arthroplasties associated with using cefuroxime and a recent meta-analysis [37] did not show any clinical difference between using cephalosporins and flucloxacillin versus cephalosporins and teicoplanin. The study recommended that local availability and cost should determine antibiotic choice.

\section{Treatment of PJIs}

High quality prospective randomized trials dictating best antibiotic therapy for PJIs and duration of treatment is currently lacking. Thus antibiotics utilized are those which have been historically used and based on clinical experience. The Infectious Diseases Society of America (IDSA), cognisant of the problem, addressed this by provision of a consensus statement, using best available evidence [9]. Accordingly, the choice of an antibiotic should be based on the bactericidal effects of the antibiotic whilst providing excellent bone and soft tissue penetration. The bactericidal effects should target surface adhering, slow growing and biofilm producing sessile bacteria as well as planktonic forms. Furthermore, the antibiotic should be well tolerated by the patient whilst adhering to local antibiotic policy and considering cost. Antibiotic therapy was conventionally delivered intravenously to attain minimum inhibitory concentration. However, upon demonstration of clinical improvement, they can be switched to an appropriate oral equivalent closely monitoring clinical progress [9, 38, 39]. Biofilm eradication has been further complicated by emergence of resistant strains and therefore, newer antimicrobial agents have been devised and in turn resistant organisms have been reported. Some of the antibiotics with direct effect on biofilm formation are discussed in the following section.

\section{Rifampin}

Originally a cornerstone of anti tuberculosis therapy, rifampin manifested itself as an important agent in treating biofilm related infections. Zimmerli et al. [40] established the role of rifampin against staphylococcal infections in a randomized controlled trial examining rifampin effects in treatment of acute PJIs with a retained implant. Rifampin has high bioavailability $(>95 \%)$ and action against organisms discovered within leukocytes and osteoblasts. Its action against slow growing bacteria has led the Société de Pathologie Infectieuse de Langue Française (SPLIF) to recommend it as a first line agent in PJIs [41]. It is worth noting though that there is a high risk of resistance when using rifampin alone and thus combination therapy is recommended. The most potent combination includes rifampin-fluoroquinolone which has demonstrated excellent clinical outcomes [40, 41].

\section{Vancomycin}

Vancomycin is a glycopeptide antibiotic used for prophylaxis and treatment of PJIs in penicillin allergic patients. Additionally, the AAOS recommends it for treatment of MRSA colonized patients and MRSA outbreaks. Recent evidence suggests that vancomycin may play a role in the prophylaxis and treatment of MRSA related PJIs after primary and revision arthroplasty surgery [42, 43]. It is disadvantaged however by its predominant intravenous use, the risk of red man syndrome and ototoxicity requiring therapeutic drug monitoring. Additionally resistance to vancomycin has been increasingly reported $[42,43]$.

\section{Newer Antibiotics}

Linezolid and daptomycin have emerged as alternatives to vancomycin and more conventional antimicrobials. Linezolid, a synthetic antimicrobial from the group of oxazolidinones has multiple advantages including high oral bioavailability and lack of cross resistance. It is effective against Staphylococci, Enterococci and multi resistant organisms such as MRSA and Methicillin resistant Staphylococcus Epidermidis (MRSE) [44, 45]. However, more recently there have been some reports on linezolid resistance as well [45].

Antibiotics have been utilized in treatment of various types of PJIs. For example, when a patient is medically unfit to undergo revision arthroplasty or is unwilling to undergo further surgery then antibiotics may be administered for long term suppression [39]. This is far from the gold standard of treatment but does have benefits such as avoiding the need for staged surgery and reduced costs. However, this strategy has specific indications including an organism which is susceptible to long term oral antibiotic suppression therapy and a prosthesis which is well fixed and functioning [46]. Table 1 includes some of the common antibiotics used for chronic suppressive therapy as suggested by the IDSA [47]. 
Table 1. Infectious Diseases Society of America (IDSA) guidelines on common antimicrobials used for chronic oral antimicrobial suppression therapy.

\begin{tabular}{|l|l|l|}
\hline & \multicolumn{1}{|c|}{ Preferred Treatment } & \multicolumn{1}{|c|}{ Alternative Treatment } \\
\hline MSSA & Cephalexin OR Cephadroxil & $\begin{array}{l}\text { Dicloxacillin } \\
\text { Clindamycin } \\
\text { Amoxicillin-clavulanate }\end{array}$ \\
\hline MRSA & $\begin{array}{l}\text { Co-trimoxazole } \\
\text { Doxycycline }\end{array}$ & N/A \\
\hline Beta Hemolytic Streptococcus & Penicillin V OR Amoxicillin & Cephalexin \\
\hline Enterococcus & Penicillin V OR Amoxicillin & N/A \\
\hline Pseudomonas & Ciprofloxacin & N/A \\
\hline
\end{tabular}

MSSA: Methicillin Susceptible Staphylococcus Aureus, MRSA: Methicillin Resistant Staphylococcus Aureus

For single or two stage revision procedures, antibiotic treatment remains essential perioperatively to ensure that infection has been adequately controlled. Intravenous administration of antibiotics for 4-6 weeks is the rule. However, conversion to oral alternatives at around 2 weeks may be an option as long as clinical and serological markers have improved and after consultation with the local microbiology department [34]. The use of antibiotic laden bone cement (ALBC) has also been popularized in conjunction with intravenous antibiotics for prophylaxis and treatment of PJIs with the potential benefits of delivering a much greater local concentration of antibiotics than achieved with systemic therapy alone. In fact, Stockley et al. [48] reported a short period of systemic antibiotic treatment when ALBC was utilized in two stage revision surgery. The most commonly used antibiotics in ALBC include a combination of vancomycin with either tobramycin or gentamicin [49]. This provides a broad spectrum of coverage for organisms commonly encountered with PJIs whilst reducing the development of resistant strains [50]. When used in temporary spacers, antibiotic dosages up to $20 \mathrm{~g}$ per $40 \mathrm{~g}$ of bone cement can be achieved without reported systemic side effects. However, if used for prophylaxis in a single stage revision or during reimplantation at the second stage revision, the maximum dose recommended is usually 1 or $2 \mathrm{~g}$ per $40 \mathrm{~g}$ of bone cement to avoid mechanical weakening [51].

Table 2. IDSA Guidelines on antibiotic treatment for different types of PJIs.

\begin{tabular}{|c|c|c|}
\hline & Staphylococcal PJI & PJI Due To Other Organism \\
\hline $\begin{array}{l}\text { Debridement and Retention of } \\
\text { Prosthesis } \\
\text { AND } \\
\text { One Stage Revision }\end{array}$ & $\begin{array}{l}\text { 2-6 weeks of pathogen specific IV antibiotic in combination with } \\
\text { rifampin 300-450mg orally twice daily } \\
\text { Followed by 3-6 months rifampin + companion drug ( } 3 \text { months for a } \\
\text { THA infection and } 6 \text { months for a TKA infection) } \\
\text { Companion agents can include ciprofloxacin/levofloxacin } \\
\text { Alternatives include co-trimoxazole/ doxycycline/1st gen cephalosporin } \\
\text { in case of allergy } \\
\text { If unable to use rifampicin, 4-6 weeks of pathogen specific IV } \\
\text { antibiotics }\end{array}$ & $\begin{array}{l}\text { 4-6 weeks of pathogen specific IV } \\
\text { or highly bioavailable oral } \\
\text { antibiotics }\end{array}$ \\
\hline $\begin{array}{l}\text { Resection Arthroplasty with or without } \\
\text { Second Stage Reimplantation }\end{array}$ & $\begin{array}{l}\text { 4-6 weeks of pathogen specific IV or highly bioavailable oral } \\
\text { antibiotics }\end{array}$ & \\
\hline
\end{tabular}

IV: intravenous, THA: total hip arthroplasty, TKA: total knee arthroplasty

In acute infections, the timing of intervention is critical in order to prevent biofilm formation. However, there remains a lot of variables including timing from onset of symptoms, timing since the primary surgery, type of prosthesis, bacteria involved, debridement technique and irrigation fluid utilized which affect infection control and hence it is difficult to formulate a single treatment strategy which will fit all cases. However, the literature suggests that the earlier an infection is diagnosed and treated with aggressive debridement with exchange of modular parts in a well fixed implant in combination with appropriate antibiotic treatment, the better the chances of infection control [52 - 64]. It is also worth noting that biofilms may rapidly reform within 24 hours following debridement and therefore a patient may benefit from more than a single debridement alongside antibiotic therapy. However there will always be some surfaces to an in situ prosthesis which debridement techniques will not reach. On the other hand, recent research has suggested that multiple debridements may have a negative impact on the success of a subsequent two stage revision procedure if those debridements are to fail [65]. A rationale for antibiotic treatment post surgery according to IDSA 
guidelines is summarized in Table 2.

\section{CONCLUSION}

As demand for total joint arthroplasty increases, so will a corresponding increase in the incidence of PJI. Infections are difficult to diagnose and once diagnosed, difficult to eradicate. This is reflected in the significant financial burden placed on healthcare systems, and considerable emotional toils inflicted on our patients.

One of the principle causes of these issues is biofilm, a network of sessile bacteria enclosed in a polymeric matrix. Aided by the implants inherent lack of immunological surveillance and defense, biofilms evade both innate immunological defenses and iatrogenic antibiotics causing problems ranging from local pain and prosthesis loosening to systemic sepsis.

Orthopaedic surgeons have addressed the considerable challenge by increased vigilance with regards to perioperative techniques ensued. This is reflected by developments in operating room environment, pre-operative screening, pre-operative planning and the administration of antibiotics. Furthermore, upon diagnosis of PJI orthopaedic surgeons have sought consensus locally in multi-disciplinary team meetings with microbiology and infectious diseases colleagues, nationally in the formulation of guidelines and internationally, to understand best management including the role of antibiotics. However many questions remain unanswered with regards to diagnosis and accurate timely treatment of biofilms and PJI.

\section{CONFLICT OF INTEREST}

Each author certifies that he or she, or a member of his or her immediate family, has no commercial interest that might pose a conflict of interest in connection with this work.

\section{ACKNOWLEDGEMENTS}

Declared none.

\section{REFERENCES}

[1] Bozic KJ, Kamath AF, Ong K, et al. Comparative epidemiology of revision arthroplasty: Failed THA poses greater clinical and economic burdens than failed TKA. Clin Orthop Relat Res 2015; 473(6): 2131-8. [http://dx.doi.org/10.1007/s11999-014-4078-8] [PMID: 25467789]

[2] Bozic KJ, Kurtz SM, Lau E, Ong K, Vail TP, Berry DJ. The epidemiology of revision total hip arthroplasty in the United States. J Bone Joint Surg Am 2009; 91(1): 128-33.

[http://dx.doi.org/10.2106/JBJS.H.00155] [PMID: 19122087]

[3] Cahill JL, Shadbolt B, Scarvell JM, Smith PN. Quality of life after infection in total joint replacement. J Orthop Surg (Hong Kong) 2008; 16(1): 58-65.

[http://dx.doi.org/10.1177/230949900801600115] [PMID: 18453662]

[4] Klouche S, Sariali E, Mamoudy P. Total hip arthroplasty revision due to infection: a cost analysis approach. Orthop Traumatol Surg Res 2010; 96(2): 124-32.

[http://dx.doi.org/10.1016/j.otsr.2009.11.004] [PMID: 20417910]

[5] Beswick AD, Elvers KT, Smith AJ, Gooberman-Hill R, Lovering A, Blom AW. What is the evidence base to guide surgical treatment of infected hip prostheses? systematic review of longitudinal studies in unselected patients. BMC Med 2012; 10: 18.

[http://dx.doi.org/10.1186/1741-7015-10-18] [PMID: 22340795]

[6] Vanhegan IS, Malik AK, Jayakumar P, Ul Islam S, Haddad FS. A financial analysis of revision hip arthroplasty: the economic burden in relation to the national tariff. J Bone Joint Surg Br 2012; 94(5): 619-23. [http://dx.doi.org/10.1302/0301-620X.94B5.27073] [PMID: 22529080]

[7] Poultsides LA, Ma Y, Della Valle AG, Chiu YL, Sculco TP, Memtsoudis SG. In-hospital surgical site infections after primary hip and knee arthroplastyincidence and risk factors. J Arthroplasty 2013; 28(3): 385-9. [http://dx.doi.org/10.1016/j.arth.2012.06.027] [PMID: 23142444]

[8] Fitzgerald RH Jr. Infected total hip arthroplasty: Diagnosis and treatment. J Am Acad Orthop Surg 1995; 3(5): 249-62. [http://dx.doi.org/10.5435/00124635-199509000-00001] [PMID: 10795031]

[9] Gehrke T, Parvizi J. Proceedings of the international consensus meeting on periprosthetic joint infection foreword. J Orthop Res 2014; 32(Suppl. 1): S2-3. [PMID: 24464894]

[10] Zimmerli W, Waldvogel FA, Vaudaux P, Nydegger UE. Pathogenesis of foreign body infection: description and characteristics of an animal model. J Infect Dis 1982; 146(4): 487-97. 
[http://dx.doi.org/10.1093/infdis/146.4.487] [PMID: 7119479]

[11] Campoccia D, Montanaro L, Arciola CR. The significance of infection related to orthopedic devices and issues of antibiotic resistance. Biomaterials 2006; 27(11): 2331-9.

[http://dx.doi.org/10.1016/j.biomaterials.2005.11.044] [PMID: 16364434]

[12] Schierholz JM, Beuth J. Implant infections: a haven for opportunistic bacteria. J Hosp Infect 2001; 49(2): 87-93. [http://dx.doi.org/10.1053/jhin.2001.1052] [PMID: 11567552]

[13] Trampuz A, Osmon DR, Hanssen AD, Steckelberg JM, Patel R. Molecular and antibiofilm approaches to prosthetic joint infection. Clin Orthop Relat Res 2003; (414): 69-88.

[http://dx.doi.org/10.1097/01.blo.0000087324.60612.93] [PMID: 12966280]

[14] Zimmerli W, Moser C. Pathogenesis and treatment concepts of orthopaedic biofilm infections. FEMS Immunol Med Microbiol 2012; 65(2): 158-68. [http://dx.doi.org/10.1111/j.1574-695X.2012.00938.x] [PMID: 22309166]

[15] Gristina AG, Naylor P, Myrvik Q. Infections from biomaterials and implants: a race for the surface. Med Prog Technol 1988-1989; 14(3-4): 205-24. [PMID: 2978593]

[16] Ribeiro M, Monteiro FJ, Ferraz MP. Infection of orthopedic implants with emphasis on bacterial adhesion process and techniques used in studying bacterial-material interactions. Biomatter 2012; 2(4): 176-94.

[http://dx.doi.org/10.4161/biom.22905] [PMID: 23507884]

[17] Fey PD, Olson ME. Current concepts in biofilm formation of Staphylococcus epidermidis. Future Microbiol 2010; 5(6): 917-33. [http://dx.doi.org/10.2217/fmb.10.56] [PMID: 20521936]

[18] Scherr TD, Heim CE, Morrison JM, Kielian T. Hiding in plain sight: Interplay between staphylococcal biofilms and host immunity. Front Immunol 2014; 5: 37. [http://dx.doi.org/10.3389/fimmu.2014.00037] [PMID: 24550921]

[19] Scherr TD, Roux CM, Hanke ML, Angle A, Dunman PM, Kielian T. Global transcriptome analysis of Staphylococcus aureus biofilms in response to innate immune cells. Infect Immun 2013; 81(12): 4363-76. [http://dx.doi.org/10.1128/IAI.00819-13] [PMID: 24042108]

[20] Barberán J. Management of infections of osteoarticular prosthesis. Clin Microbiol Infect 2006; 12(Suppl. 3): 93-101. [http://dx.doi.org/10.1111/j.1469-0691.2006.01400.x] [PMID: 16669932]

[21] Kluytmans J, van Belkum A, Verbrugh H. Nasal carriage of Staphylococcus aureus: epidemiology, underlying mechanisms, and associated risks. Clin Microbiol Rev 1997; 10(3): 505-20. [PMID: 9227864]

[22] Moroski NM, Woolwine S, Schwarzkopf R. Is preoperative staphylococcal decolonization efficient in total joint arthroplasty. J Arthroplasty 2015; 30(3): 444-6.

[http://dx.doi.org/10.1016/j.arth.2014.10.017] [PMID: 25453634]

[23] Chen AF, Wessel CB, Rao N. Staphylococcus aureus screening and decolonization in orthopaedic surgery and reduction of surgical site infections. Clin Orthop Relat Res 2013; 471(7): 2383-99. [http://dx.doi.org/10.1007/s11999-013-2875-0] [PMID: 23463284]

[24] Giannoudis PV, Parker J, Wilcox MH. Methicillin-resistant Staphylococcus aureus in trauma and orthopaedic practice. J Bone Joint Surg Br 2005; 87(6): 749-54.

[http://dx.doi.org/10.1302/0301-620X.87B6.16292] [PMID: 15911652]

[25] Goyal N, Miller A, Tripathi M, Parvizi J. Methicillin-resistant Staphylococcus aureus (MRSA): colonisation and pre-operative screening. Bone Joint J 2013; 95-B(1): 4-9. [http://dx.doi.org/10.1302/0301-620X.95B1.27973] [PMID: 23307666]

[26] Dancer SJ. Importance of the environment in meticillin-resistant Staphylococcus aureus acquisition: the case for hospital cleaning. Lancet Infect Dis 2008; 8(2): 101-13. [http://dx.doi.org/10.1016/S1473-3099(07)70241-4] [PMID: 17974481]

[27] Infection: prevention and control of healthcare-associated infections in primary and commu-nity care 2012. updated 2012. Available from: http://www.nice.org.uk/guidance/cg139/evidence/cg139-infection-control-full-guideline3.

[28] Murphy E, Spencer SJ, Young D, Jones B, Blyth MJ. MRSA colonisation and subsequent risk of infection despite effective eradication in orthopaedic elective surgery. J Bone Joint Surg Br 2011; 93(4): 548-51. [http://dx.doi.org/10.1302/0301-620X.93B4.24969] [PMID: 21464498]

[29] Peel TN, Cheng AC, Buising KL, Choong PF. Microbiological aetiology, epidemiology, and clinical profile of prosthetic joint infections: are current antibiotic prophylaxis guidelines effective? Antimicrob Agents Chemother 2012; 56(5): 2386-91. [http://dx.doi.org/10.1128/AAC.06246-11] [PMID: 22314530]

[30] 104 Antibiotic prophylaxis in surgery A national clinical guideline 2008 July; updated April 2014. Available from: http://sign.ac.uk/pdf/sign104.pdf. 
[31] Fogelberg EV, Zitzmann EK, Stinchfield FE. Prophylactic penicillin in orthopaedic surgery. J Bone Joint Surg Am 1970; $52(1)$ : 95-8. [PMID: 5197855]

[32] Meehan J, Jamali AA, Nguyen H. Prophylactic antibiotics in hip and knee arthroplasty. J Bone Joint Surg Am 2009; 91(10): 2480-90. [http://dx.doi.org/10.2106/JBJS.H.01219] [PMID: 19797586]

[33] Illingworth KD, Mihalko WM, Parvizi J, et al. How to minimize infection and thereby maximize patient outcomes in total joint arthroplasty: a multicenter approach: AAOS exhibit selection. J Bone Joint Surg Am 2013; 95(8): e50. [http://dx.doi.org/10.2106/JBJS.L.00596] [PMID: 23595076]

[34] Osmon DR, Berbari EF, Berendt AR, et al. Executive summary: diagnosis and management of prosthetic joint infection: clinical practice guidelines by the Infectious Diseases Society of America. Clin Infect Dis 2013; 56(1): 1-10. [http://dx.doi.org/10.1093/cid/cis966] [PMID: 23230301]

[35] Aujla RS, Bryson DJ, Gulihar A, Taylor GJ. Trends in orthopaedic antimicrobial prophylaxis in the UK between 2005 and 2011. Ann R Coll Surg Engl 2013; 95(7): 495-502. [http://dx.doi.org/10.1308/003588413X13629960047038] [PMID: 24112496]

[36] Jenkins PJ, Teoh K, Simpson PM, Dave J, Simpson AH, Breusch S. Clostridium difficile in patients undergoing primary hip and knee replacement. J Bone Joint Surg Br 2010; 92(7): 994-8.

[http://dx.doi.org/10.1302/0301-620X.92B7.23412] [PMID: 20595121]

[37] AlBuhairan B, Hind D, Hutchinson A. Antibiotic prophylaxis for wound infections in total joint arthroplasty: a systematic review. J Bone Joint Surg Br 2008; 90(7): 915-9. [http://dx.doi.org/10.1302/0301-620X.90B7.20498] [PMID: 18591602]

[38] Sukeik M, Haddad FS. Two-stage procedure in the treatment of late chronic hip infectionsspacer implantation. Int J Med Sci 2009; 6(5): 253-7.

[http://dx.doi.org/10.7150/ijms.6.253] [PMID: 19834591]

[39] Sukeik MT, Haddad FS. Management of periprosthetic infection in total hip arthroplasty. Orthop Trauma 2009; 23(5): 342-9. [http://dx.doi.org/10.1016/j.mporth.2009.08.009]

[40] Zimmerli W, Widmer AF, Blatter M, Frei R, Ochsner PE. Role of rifampin for treatment of orthopedic implant-related staphylococcal infections: a randomized controlled trial. JAMA 1998; 279(19): 1537-41. [http://dx.doi.org/10.1001/jama.279.19.1537] [PMID: 9605897]

[41] Coiffier G, Albert JD, Arvieux C, Guggenbuhl P. Optimizing combination rifampin therapy for staphylococcal osteoarticular infections. Joint Bone Spine 2013; 80(1): 11-7. [http://dx.doi.org/10.1016/j.jbspin.2012.09.008] [PMID: 23332140]

[42] Liu C, Kakis A, Nichols A, Ries MD, Vail TP, Bozic KJ. Targeted use of vancomycin as perioperative prophylaxis reduces periprosthetic joint infection in revision TKA. Clin Orthop Relat Res 2014; 472(1): 227-31. [http://dx.doi.org/10.1007/s11999-013-3029-0] [PMID: 23645338]

[43] Smith EB, Wynne R, Joshi A, Liu H, Good RP. Is it time to include vancomycin for routine perioperative antibiotic prophylaxis in total joint arthroplasty patients? J Arthroplasty 2012; 27(8)(Suppl.): 55-60. [http://dx.doi.org/10.1016/j.arth.2012.03.040] [PMID: 22608685]

[44] Corti G, Cinelli R, Paradisi F. Clinical and microbiologic efficacy and safety profile of linezolid, a new oxazolidinone antibiotic. Int J Antimicrob Agents 2000; 16(4): 527-30. [http://dx.doi.org/10.1016/S0924-8579(00)00290-9] [PMID: 11118873]

[45] Tian Y, Li T, Zhu Y, Wang B, Zou X, Li M. Mechanisms of linezolid resistance in staphylococci and enterococci isolated from two teaching hospitals in Shanghai, China. BMC Microbiol 2014; 14: 292. [http://dx.doi.org/10.1186/s12866-014-0292-5] [PMID: 25420718]

[46] Segreti J, Nelson JA, Trenholme GM. Prolonged suppressive antibiotic therapy for infected orthopedic prostheses. Clin Infect Dis 1998; 27(4): 711-3. [http://dx.doi.org/10.1086/514951] [PMID: 9798021]

[47] Osmon DR, Berbari EF, Berendt AR, et al. Diagnosis and management of prosthetic joint infection: clinical practice guidelines by the Infectious Diseases Society of America. Clin Infect Dis 2013; 56(1): e1-e25. [http://dx.doi.org/10.1093/cid/cis803] [PMID: 23223583]

[48] Stockley I, Mockford BJ, Hoad-Reddick A, Norman P. The use of two-stage exchange arthroplasty with depot antibiotics in the absence of long-term antibiotic therapy in infected total hip replacement. J Bone Joint Surg Br 2008; 90(2): 145-8. [http://dx.doi.org/10.1302/0301-620X.90B2.19855] [PMID: 18256078]

[49] Scott CP, Higham PA. Antibiotic bone cement for the treatment of Pseudomonas aeruginosa in joint arthroplasty: comparison of tobramycin and gentamicin-loaded cements. J Biomed Mater Res B Appl Biomater 2003; 64(2): 94-8. [http://dx.doi.org/10.1002/jbm.b.10515] [PMID: 12516083]

[50] Anagnostakos K, Fürst O, Kelm J. Antibiotic-impregnated PMMA hip spacers: Current status. Acta Orthop 2006; 77(4): 628-37. [http://dx.doi.org/10.1080/17453670610012719] [PMID: 16929441] 
[51] Hanssen AD, Osmon DR. Assessment of patient selection criteria for treatment of the infected hip arthroplasty. Clin Orthop Relat Res 2000; (381): 91-100. [PMID: 11127676]

[52] Azzam KA, Seeley M, Ghanem E, Austin MS, Purtill JJ, Parvizi J. Irrigation and debridement in the management of prosthetic joint infection: traditional indications revisited. J Arthroplasty 2010; 25(7): 1022-7. [http://dx.doi.org/10.1016/j.arth.2010.01.104] [PMID: 20378306]

[53] Bradbury T, Fehring TK, Taunton M, et al. The fate of acute methicillin-resistant Staphylococcus aureus periprosthetic knee infections treated by open debridement and retention of components. J Arthroplasty 2009; 24(6)(Suppl.): 101-4. [http://dx.doi.org/10.1016/j.arth.2009.04.028] [PMID: 19553077]

[54] Crockarell JR, Hanssen AD, Osmon DR, Morrey BF. Treatment of infection with débridement and retention of the components following hip arthroplasty. J Bone Joint Surg Am 1998; 80(9): 1306-13. [PMID: 9759815]

[55] Krasin E, Goldwirth M, Hemo Y, Gold A, Herling G, Otremski I. Could irrigation, debridement and antibiotic therapy cure an infection of a total hip arthroplasty? J Hosp Infect 2001; 47(3): 235-8. [http://dx.doi.org/10.1053/jhin.2000.0809] [PMID: 11247685]

[56] Marculescu CE, Berbari EF, Hanssen AD, et al. Outcome of prosthetic joint infections treated with debridement and retention of components. Clin Infect Dis 2006; 42(4): 471-8. [http://dx.doi.org/10.1086/499234] [PMID: 16421790]

[57] Martínez-Pastor JC, Muñoz-Mahamud E, Vilchez F, et al. Outcome of acute prosthetic joint infections due to gram-negative bacilli treated with open debridement and retention of the prosthesis. Antimicrob Agents Chemother 2009; 53(11): $4772-7$. [http://dx.doi.org/10.1128/AAC.00188-09] [PMID: 19687237]

[58] Mont MA, Waldman B, Banerjee C, Pacheco IH, Hungerford DS. Multiple irrigation, debridement, and retention of components in infected total knee arthroplasty. J Arthroplasty 1997; 12(4): 426-33. [http://dx.doi.org/10.1016/S0883-5403(97)90199-6] [PMID: 9195319]

[59] Silva M, Tharani R, Schmalzried TP. Results of direct exchange or debridement of the infected total knee arthroplasty. Clin Orthop Relat Res 2002; (404): 125-31. [http://dx.doi.org/10.1097/00003086-200211000-00022] [PMID: 12439250]

[60] Sukeik M, Patel S, Haddad FS. Aggressive early débridement for treatment of acutely infected cemented total hip arthroplasty. Clin Orthop Relat Res 2012; 470(11): 3164-70. [http://dx.doi.org/10.1007/s11999-012-2500-7] [PMID: 22826016]

[61] Teeny SM, Dorr L, Murata G, Conaty P. Treatment of infected total knee arthroplasty. Irrigation and debridement versus two-stage reimplantation. J Arthroplasty 1990; 5(1): 35-9.

[http://dx.doi.org/10.1016/S0883-5403(06)80007-0] [PMID: 2319246]

[62] Cobo J, Miguel LG, Euba G, et al. Early prosthetic joint infection: outcomes with debridement and implant retention followed by antibiotic therapy. Clin Microbiol Infect 2011; 17(11): 1632-7. [http://dx.doi.org/10.1111/j.1469-0691.2010.03333.x] [PMID: 20678178]

[63] Van Kleunen JP, Knox D, Garino JP, Lee GC. Irrigation and débridement and prosthesis retention for treating acute periprosthetic infections. Clin Orthop Relat Res 2010; 468(8): 2024-8. [http://dx.doi.org/10.1007/s11999-010-1291-y] [PMID: 20224960]

[64] Koh IJ, Han SB, In Y, Oh KJ, Lee DH, Kim TK. Open debridement and prosthesis retention is a viable treatment option for acute periprosthetic joint infection after total knee arthroplasty. Arch Orthop Trauma Surg 2015; 135(6): 847-55. [http://dx.doi.org/10.1007/s00402-015-2237-3] [PMID: 25947069]

[65] Sherrell JC, Fehring TK, Odum S, et al. The Chitranjan Ranawat Award: fate of two-stage reimplantation after failed irrigation and débridement for periprosthetic knee infection. Clin Orthop Relat Res 2011; 469(1): 18-25. [http://dx.doi.org/10.1007/s11999-010-1434-1] [PMID: 20582495]

(C) Mirza et al.; Licensee Bentham Open

This is an open access article licensed under the terms of the Creative Commons Attribution-Non-Commercial 4.0 International Public License (CC BY-NC 4.0) (https://creativecommons.org/licenses/by-nc/4.0/legalcode), which permits unrestricted, non-commercial use, distribution and reproduction in any medium, provided the work is properly cited. 